\title{
Blunt Abdominal Trauma Combined with Postoperative Atelectasis and Mediastinal Shift: A Case Report
}

\author{
Suya Zhang1, Hongshun $\mathrm{Xu}^{2}$, Yubin Kou ${ }^{1,2^{*}}$ \\ ${ }^{1}$ Shanghai Baoshan District Hospital of Integrated Traditional and Western Medicine, Shanghai, China \\ ${ }^{2}$ Mission Médicale Chinoise Du Maroc, Department of General Surgery of Mohamed V Chefchaouen Hôpital, \\ Chefchaouen, Maroc \\ Email: "koagrace@sina.com
}

Received 8 January 2016; accepted 23 January 2016; published 28 January 2016

Copyright $(02016$ by authors and OALib.

This work is licensed under the Creative Commons Attribution International License (CC BY).

http://creativecommons.org/licenses/by/4.0/

(c) () Open Access

\begin{abstract}
Blunt abdominal trauma is a frequent emergency and is also associated with significant morbidity and mortality. Spleen is the commonest organ injured. In this study, we meet a special complication after splenectomy, atelectasis and mediastinal shift, and this is the complication with hemodynamic unstable. Without bronchoscopy, the patient is told to inspire deeply by blowing balloons with pressure $8-10 \mathrm{~cm} \mathrm{H}_{2} \mathrm{O}$ and recovered uneventfully.
\end{abstract}

Keywords

BAT, Atelectasis, Mediastinal Shift, Splenectomy, Complication

Subject Areas: Emergency \& Critical Care

\section{Introduction}

A 16-year-old young man who suffered traffic accident injury within 4 hours was presented with hemodynamic instability and slight dyspnea: physical examination: HR > $120 \mathrm{bpm}$, BP 80/60 mmHg; lab results: WBC10.3 × $10^{9} / \mathrm{L}, \mathrm{RBC} 3.00 \times 10^{12} / \mathrm{L}, \mathrm{HCT} 31.7 \%$, HGB96g/L; ultrasonography and radiographic investigation (including $\mathrm{CT}$ ): left pneumothorax and rib fracture, rupture of spleen, pelvis fracture.

\section{Surgical Intervention}

With aggressive fluid resuscitation simultaneously, this patient was undertaken an urgent laparotomy. Before operation, left pneumothorax required intercostals drainage. During operation, we found that the patient had a

\footnotetext{
*Corresponding author.
}

How to cite this paper: Zhang, S.Y., Xu, H.S. and Kou, Y.B. (2016) Blunt Abdominal Trauma Combined with Postoperative Atelectasis and Mediastinal Shift: A Case Report. Open Access Library Journal, 3: e2358. 
mortal hem peritoneum with a continuous blood loss about $4000 \mathrm{ml}$. This is a case of central rupture of spleen (Figure 1). Ligation of splenic pedicle done well was the most important for splenectomy and drainage was necessarily carried out after surgery.

\section{Complication after Operation}

7 days later, the patient again presented with an acute dyspnea, increased heart rate, and left lung sound was reduced. On presentation his vital signs were within normal limits and oxygen-saturation was 95\% on $2 \mathrm{~L}$ of oxygen. Chest roentgenogram (Figure 2) demonstrated leftward mediastinal shift and left complete atelectasis. Without bronchoscopy, blowing balloons was available and prompt treatment for the young patient with a pressure $8-10 \mathrm{~cm} \mathrm{H}_{2} \mathrm{O}$ (Figure 3). After 5 days with anti-infection preventative and blowing balloons continuously, the patient's vital signs and chest x-ray normalized (Figure 4). The patient recovered unevenfully.

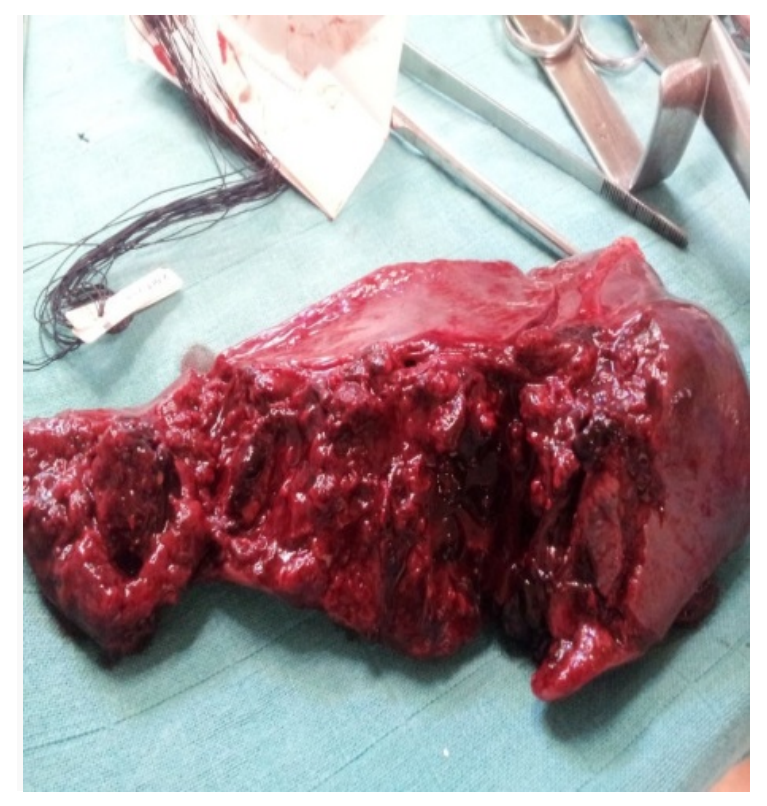

Figure 1. Rupture spleen.

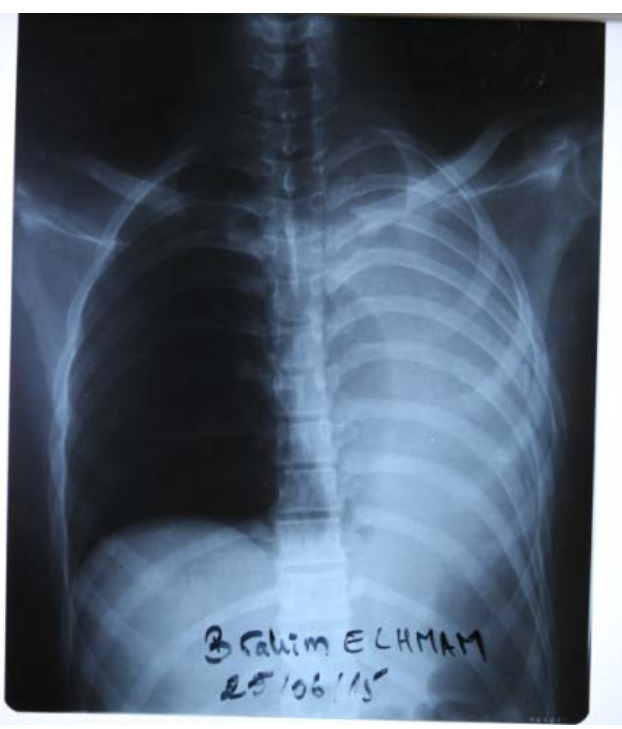

Figure 2. Left atelectasis and mediastinal shift. 


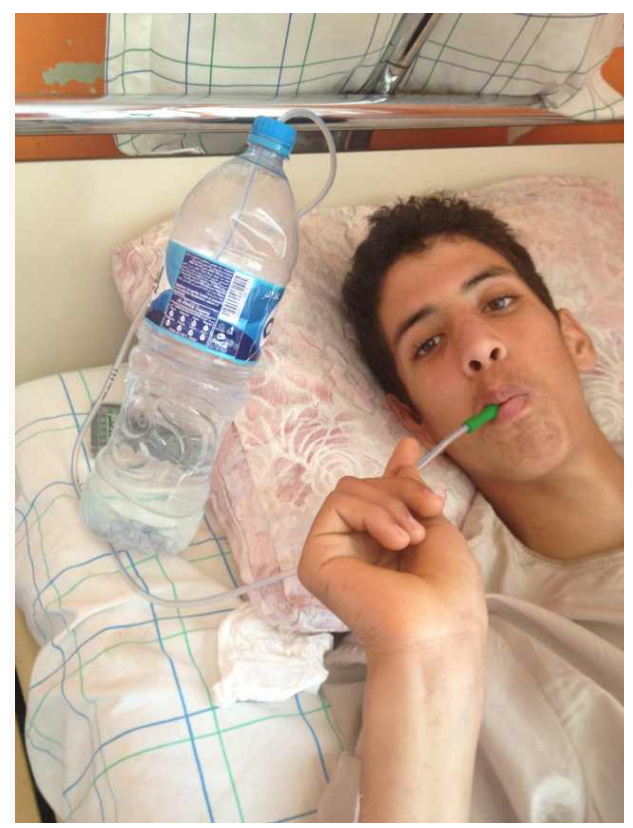

Figure 3. Blowing balloon deeply.

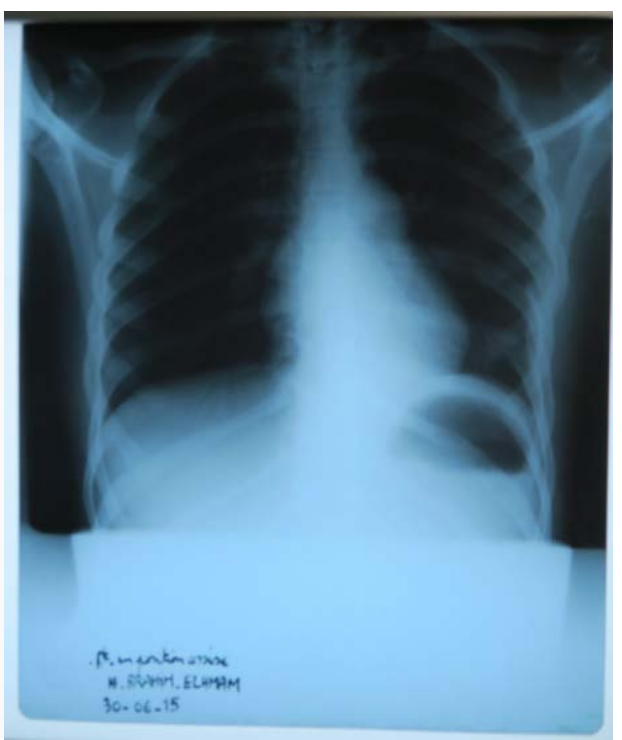

Figure 4. Recovery of atelectasis.

\section{Discussion}

Blunt abdominal trauma (BAT) is a frequent emergency and is associated with significant morbidity and mortality all over the world. Nikhil Mehta et al. [1] concluded that motor vehicle accident (53\%) was the most common mechanism of injury and spleen (53\%) was the commonest organ injured, the most common surgery performed was splenectomy (30\%). Most common extra-abdominal injury was rib fracture in $20 \%$.

There was a postoperative complication with hemodynamic unstable, complete atelectasis and mediastinum shift, which need to be treated immediately [2]. There were three sets of mechanisms about atelectasis have been proposed that would cause or contribute to the atelectasis, including compression of lung tissue, absorption of alveolar air, and impairment of surfactant function [3]. Development of atelectasis is associated with decreased lung compliance, impairment of oxygenation, increased pulmonary vascular resistance, and development of lung injury. The adverse effects of atelectasis persist into the postoperative period and can impact patient recovery [4]. 


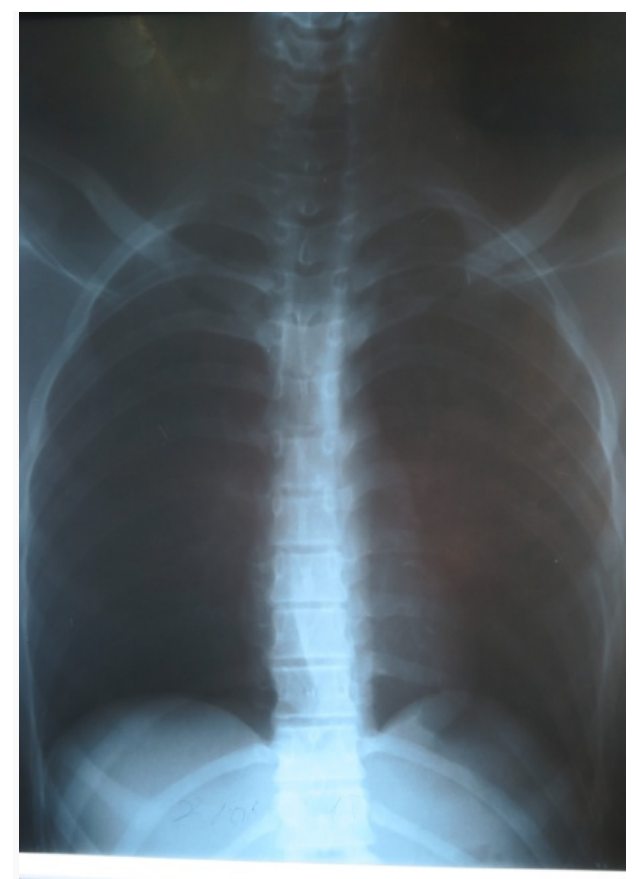

Figure 5. X-ray before operation.

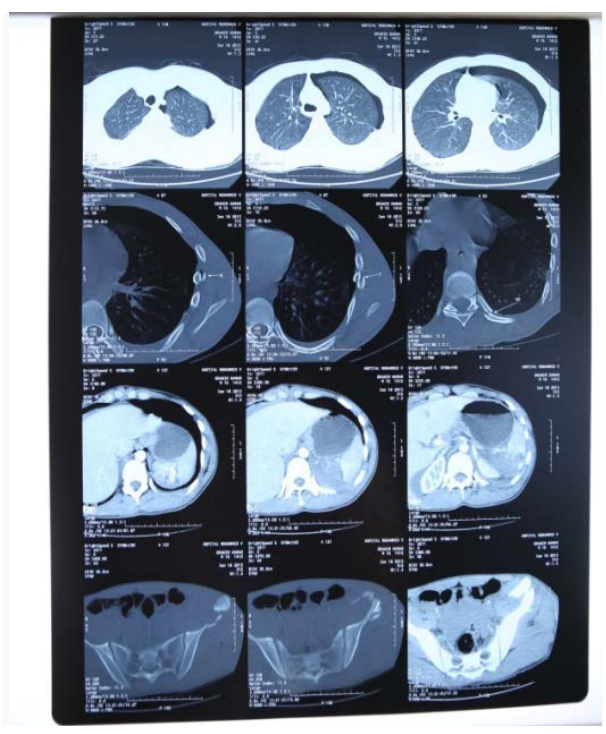

Figure 6. Pneumothorax before operation.

Fortunately, pulmonary atelectasis can return toward normal after deep inflation of the lung [5]. Patients who undertook abdominal surgery breathed rapidly with small tidal volumes and were unwilling or unable to inspire deeply. And also pain was traditionally assumed to be the principal causative factor for formation of the atelectasis, even though that was equivocal with other study [6].

Our case had three factors which caused and contributed to the development the pulmonary atelectasis after operation, pneumothorax, rib fracture and splenectomy (traumatic rupture of spleen (Figure 5 and Figure 6). It was easily to form pulmonary atelectasis. He was told to inspire deeply by blowing balloons with pressure 8 - 10 $\mathrm{cm} \mathrm{H}_{2} \mathrm{O} .5$ days later, with anti-infection preventative and blowing balloons continuously, the patient's vital signs and chest $\mathrm{X}$-ray normalized. The patient recovered uneventfully. 


\section{Conclusion}

This case demonstrates the hemodynamic unstability that can occur as a result of pulmonary atelectasis and mediastinal shift after splenectomy, combined with rib fracture. Atelectasis and mediastinal shift can cause hemodynamic unstability that needs management urgently. Without bronchoscopy, blowing balloon slaw is effective and simple, and clinicians may have a try when face up this kind of rare case.

\section{References}

[1] Mehta, N., Babu, S. and Venugopal, K. (2014) An Experience with Blunt Abdominal Trauma: Evaluation, Management and Outcome. Clinics and Practice; 4, 599. http://dx.doi.org/10.4081/cp.2014.599

[2] Nechala, P., Tremblay, A. and Grondin, S.C. (2006) Bronchial Obstruction Ca-Using Mediastinal Shiftand Hemodynamic Compromise. The Annals of Thoracic Surgery, 82, 1916. http://dx.doi.org/10.1016/j.athoracsur.2005.10.043

[3] Rothen, H.G. (1998) HU: Ventilation and Perfusion Matching, Anesthesia Biologic Foundations. In: Yaksh, T.L., Lynch, C.L., Zapol, W.M., Maze, M., Biebuyck, J.F. and Saidman, L.J., Eds., Lippincott-Raven, Philadelphia, 13491366.

[4] Duggan, M. and Kavanagh, B.P. (1963) Pulmonary Atelectasis. Anesthesiology, 102, 838-854. http://dx.doi.org/10.1097/00000542-200504000-00021

[5] Bendixen, H.H., Hedley-Whyte, J., Chir, B. and Laver, M.B. (1963) Impaired Oxygenation Insurgical Patients during General Anesthesia with Controlled Ventilation. New England Journal of Medicine, 269, 991-996. http://dx.doi.org/10.1056/NEJM196311072691901

[6] Wahba, RW. (1991) Perioperative Functional Residual Capacity. Canadian Journal of Anesthesia, 38, 384-400. http://dx.doi.org/10.1007/BF03007630 